\title{
The effect of molecular weight on the material properties of biosynthe- sized poly(4-hydroxybutyrate)
}

Luciano F. Boesel, Sylvaine Le Meur, Linda Thöny-Meyer, Qun Ren*

Empa - Swiss Federal Laboratories for Materials Science and Technology, Laboratory for Biomaterials, Lerchenfeldstrasse 5, 9014, St. Gallen, Switzerland

Corresponding author: qun.ren@empa.ch, Tel: +41587657688

Dated: March 20, 2014

\section{ABSTRACT:}

Poly(4-hydroxybutyrate) (P4HB) is a bacterial polyhydroxyalkanoate with interesting biological and physicochemical properties for the use in biomedical applications. The synthesis of P4HB through a fermentation process often leads to a polymer with a too high molecular weight, making it difficult to process it further by solvent- or meltprocessing. In this work P4HB was degraded to obtain polymers with a molecular weight ranging from $1,5 \cdot 10^{3} \mathrm{~g} / \mathrm{mol}$ to $1,0 \cdot 10^{6} \mathrm{~g} / \mathrm{mol}$ by using a method established in our laboratory. We studied the effect of the change in molecular weight on thermal and mechanical properties. The decrease of the molecular weight led to an increase in the degree of crystallinity of the polymer. Regarding the tensile mechanical properties, the molecular weight played a more prominent role than the degree of crystallinity in the evolution of the properties for the different polymer fractions. The method presented herein allows the preparation of polymer fractions with easier processability and still adequate thermal and mechanical properties for biomedical applications.

Keywords:P4HB, molecular weight, mechanical properties

This document is the accepted manuscript version of the following article: Boese1, L. F., Le Meur, S., Thöny-Meyer, L., \& Ren, Q. (2014). The effect of molecular weight on the material properties of biosynthesized poly(4-hydroxybutyrate). International Journal of Biological Macromolecules, 71, 124-130. https://doi.org/10.1016/ j.ijbiomac.2014.04.015

This manuscript version is made available under the CC-BY-NC-ND 4.01icense http:// creativecommons.org/1icenses/by-nc-nd/4.0/ 


\section{Introduction}

Poly(4-hydroxybutyrate) ( $\mathrm{P} 4 \mathrm{HB})$ is a natural polyester that has been approved for use as an absorbable suture by the FDA in 2007. P4HB is a polyhydroxyalkanoate, a family of polymers synthesized by microorganisms as carbon and energy storage compounds.

The chemical synthesis of P4HB has been attempted; however, it is generally considered impossible to produce the polyester by this method with sufficiently high molecular weight necessary for most applications. [1] Furthermore, the chemically produced $\mathrm{P} 4 \mathrm{HB}$ may contain residual metal catalysts that are used in the chemical synthesis of the polymer. Thus, $\mathrm{P} 4 \mathrm{HB}$ is produced through a fermentation rather than a chemical process. To produce $\mathrm{P} 4 \mathrm{HB}$ homopolymers, recombinant Escherichia coli strains were used. By introducing the PHB synthase gene ( $p h b C$ ) from Ralstonia eutropha and a 4-hydroxybutyric acid-coenzyme A transferase gene (orfZ) from Clostridium kluyveri, E. coli strains XL1-Blue and JM109 were able to produce P4HB when 4-hydroxybutyric acid (4HB) was supplied as a precursor in the culture medium. [2, 3] It was also reported that an E. coli JM109 mutant carrying two plasmids was able to synthesize P4HB using Lysogeny broth (LB) medium containing only glucose without P4HB related precursor such as 4HB. [4]

The interest on using P4HB in medical applications derives from its inherent biocompatibility and adequate physical properties. Research has focused on heart valves, vascular grafts, scaffolds, and sutures. [3, 5] Besides being biocompatible, the degradation process of $\mathrm{P} 4 \mathrm{HB}$ is also milder than that of other biomedical polymers: $\mathrm{P} 4 \mathrm{HB}$ degrades via surface erosion, which minimizes the burst release of acids [5]. Moreover, the degradation product, 4hydroxybutyrate, is a metabolite commonly found in the human body. [6] Recent studies have shown that both fiber monofilaments [7] and fiber meshes [8] made of P4HB degraded without causing any adverse reactions to the surrounding soft tissue (muscle and abdominal wall, respectively). Regarding physical and chemical properties, P4HB provides a combination of properties that makes it very useful in biomedical applications: solubility in a range of polar solvents (e.g., acetone), elastomeric character at room and body temperature, low melt temperature (that is, easy melt processability), high molecular weight, very high ductility ( $>200 \%)$, and a moderate resorption rate in vivo. [5]

Despite these characteristics and the large amount of data on in vivo animal studies, [5, 7-9] there has been little attention dedicated to the physical properties of P4HB. Specifically, no work has concentrated on studying changes in mechanical and thermal properties of $\mathrm{P} 4 \mathrm{HB}$ as a function of molecular weight. Given that the bacterial synthesis

of these polymers usually leads to very high molecular weight $\left(\mathrm{Mn} \sim 10^{6} \mathrm{~g} / \mathrm{mol}\right.$ ) and that at such high values the melt and solvent processability are compromised, we report in this study how the acid-catalyzed hydrolysis affects the mechanical and thermal properties of the biosynthesized P4HB.

\section{Experimental}

\subsection{Biosynthesis of $P 4 H B$}

All chemicals were purchased from Sigma-Aldrich (Buchs, Switzerland). Escherichia coli JM109 carrying plasmid pKSSE5.3 was used in this study for P4HB production. pKSSE5.3 contains a PHA synthase gene ( $p h a C$ ) from 
Ralstonia eutropha and a 4-hydroxybutyric acid-coenzyme A transferase gene (orfZ) from Clostridium kluyveri. [2] The JM109 recombinant cells were used to inoculate a $10 \mathrm{~mL} \mathrm{LB}$ culture in a $50 \mathrm{~mL}$ flask. The cells were incubated at $37{ }^{\circ} \mathrm{C}$ and $150 \mathrm{rpm}$ overnight. The culture was then used to inoculate $200 \mathrm{~mL}$ of preculture using modified E2 medium in a $1 \mathrm{~L}$ shake flask with a dilution of 1:20 $\left(\mathrm{v} \mathrm{v} \mathrm{v}^{-1}\right)$. Modified E2 medium contained the following constituents: $\mathrm{NaNH}_{4} \mathrm{HPO}_{4} \cdot 4 \mathrm{H}_{2} \mathrm{O} 3,5 \mathrm{~g} \mathrm{~L}^{-1}, \mathrm{KH}_{2} \mathrm{PO}_{4} 3,7 \mathrm{~g} \mathrm{~L}^{-1}$, and $\mathrm{K}_{2} \mathrm{HPO}_{4} 7,5 \mathrm{~g} \mathrm{~L}^{-1}$, dissolved in $1 \mathrm{~L}$ of water. One $\mathrm{mL} \mathrm{L}^{-1}$ of $1 \mathrm{M}$ $\mathrm{MgSO}_{4} \cdot 7 \mathrm{H}_{2} \mathrm{O}$ was added to the medium. One $\mathrm{mL} \mathrm{L}^{-1}$ of trace elements (TE) dissolved in $1 \mathrm{M} \mathrm{HCl}$ was also added. TE contained: $\mathrm{FeSO}_{4} \cdot 7 \mathrm{H}_{2} \mathrm{O} 2,78 \mathrm{~g} \mathrm{~L}^{-1}, \mathrm{CaCl}_{2} \cdot 2 \mathrm{H}_{2} \mathrm{O} 1,47 \mathrm{~g} \mathrm{~L}^{-1}, \mathrm{MnCl}_{2} \cdot 4 \mathrm{H}_{2} \mathrm{O} 1,98 \mathrm{~g} \mathrm{~L}^{-1}, \mathrm{CoCl}_{2} \cdot 6 \mathrm{H}_{2} \mathrm{O} 2,38 \mathrm{~g} \mathrm{~L}^{-1}$, $\mathrm{CuCl}_{2} \cdot 2 \mathrm{H}_{2} \mathrm{O} 0,17 \mathrm{~g} \mathrm{~L}^{-1}, \mathrm{ZnSO}_{4} \cdot 7 \mathrm{H}_{2} \mathrm{O} 0,29 \mathrm{~g} \mathrm{~L}^{-1} .10 \mathrm{~g} \mathrm{~L}^{-1}$ of xylose and $4 \mathrm{~g} \mathrm{~L}^{-1}$ of Na-4HB were used as the growth substrate and the precursor for P4HB synthesis, respectively. $1 \mathrm{~g} \mathrm{~L}^{-1}$ of NZ-amines and $0,015 \mathrm{~g} \mathrm{~L}^{-1}$ of thiamine were supplemented to support the growth. $100 \mu \mathrm{g} \mathrm{mL}^{-1}$ of ampicillin was added to maintain the plasmid. The preculture was incubated at $150 \mathrm{rpm}$ and $32{ }^{\circ} \mathrm{C}$ for $16 \mathrm{~h}$. It was then transferred to $600 \mathrm{~mL}$ modified E2 medium in a total volume 1,4 L bioreactor (Infors AG, Bottmingen, $\mathrm{CH}$ ) equipped with standard control units. The initial optical density $\left(\mathrm{OD}_{600}\right)$ value in the bioreactor was between 0,10 and 0,30 . Temperature was controlled at $32{ }^{\circ} \mathrm{C}$ with an external circulating water bath, and $\mathrm{pH}$ was maintained at 7,0 $\pm 0,1$ by automatic addition of $25 \% \mathrm{NaOH}$ or $30 \% \mathrm{H}_{3} \mathrm{PO}_{4}$. Dissolved oxygen tension was monitored continuously with an oxygen probe (Infors AG, Bottmingen, Switzerland) and kept always above $30 \%$ oxygen saturation. The agitation was set at $500 \mathrm{rpm}$.

\subsection{Extraction of $P 4 H B$}

P4HB was extracted directly from the lyophilized cells (1 mbar, 48 to $144 \mathrm{~h}$ ). Cells were transferred into pure dichloromethane ( $50 \mathrm{~g}$ dried cell biomass in $1,5 \mathrm{~L}$ solvent). After the suspension was stirred at $60{ }^{\circ} \mathrm{C}$ for $90 \mathrm{~min}$ or at room temperature for 16 hours, the solution was filtered with pressure and concentrated by distillation at $40{ }^{\circ} \mathrm{C}$ and $400 \mathrm{mbar}$ in a rotary evaporator until the solution became viscous. The viscous solution was added dropwise under stirring to a 6-fold quantity of ice-cold methanol. P4HB was precipitated and dried in a vacuum dryer (VTR 5036, Heraeus, Hanau, Germany) for at least $24 \mathrm{~h}$ at $30{ }^{\circ} \mathrm{C}$ and 30 mbar. The polymer was stored at $-20^{\circ} \mathrm{C}$.

\subsection{Degradation procedure}

A solution of $1 \% \mathrm{P} 4 \mathrm{HB}$ in chloroform was prepared by dissolving the polymer overnight at room temperature in the solvent. The catalyst solution was prepared by adding $66 \mu \mathrm{L}$ of sulphuric acid (95-97\%) in $10 \mathrm{~mL}$ methanol. Afterwards, the polymer solution was heated in reflux at $55{ }^{\circ} \mathrm{C}$ until evaporation of chloroform started, at which point the catalyst solution was added $(\mathrm{t}=0)$. At each predefined degradation time point, $500 \mathrm{~mL}$ of the degradation solution were added to $500 \mathrm{~mL}$ pre-cooled water in a separation funnel, mixed, and allowed to separate. The bottom phase, containing the degraded polymer, was then dropped into $1 \mathrm{~L}$ of stirred, ice-cold methanol in order to precipitate it. The polymer was subsequently removed from the methanol, dried overnight under vacuum at $40{ }^{\circ} \mathrm{C}$ and stored at $-20{ }^{\circ} \mathrm{C}$ until further use.

\subsection{Characterization}

The native and degraded polymers were characterized by gel permeation chromatography (GPC), differential scanning calorimetry (DSC) and tensile tests. 
GPC was performed using a differential refractive index detector (Viscotek, Houston, USA). Each polymer sample was dissolved in chloroform $(0,1 \%)$, and aliquots of $100 \mu \mathrm{L}$ of the polymer solution were injected and separated on three sequentially coupled size exclusion chromatography (SEC) columns $\left(300 \mathrm{~mm} \times 8 \mathrm{~mm}\right.$, pore sizes of $10^{3}, 10^{5}$, and $10^{7} \AA$, Polymer Standard Services - PSS, Mainz, Germany) at $35{ }^{\circ} \mathrm{C}$, applying a flow rate of $0,5 \mathrm{~mL} / \mathrm{min}$ of chloroform. Calibration was performed with 10 narrow standard polystyrene (PS) samples supplied by PSS (from $2 \times$ $10^{3} \mathrm{~g} / \mathrm{mol}$ to $\left.2,13 \times 10^{6} \mathrm{~g} / \mathrm{mol}\right)$. Both number-average $\left(M_{n}\right)$ and weight-average $\left(M_{w}\right)$ molar masses were determined, as well as the polydispersity index ( $\left.\mathrm{PI}=M_{w} / M_{n}\right)$.

DSC was performed using a Mettler-Toledo DSC $822^{e}$ apparatus. The following 3-step program was applied to all specimens: first heating from $-100{ }^{\circ} \mathrm{C}$ to $100{ }^{\circ} \mathrm{C}$ at $10{ }^{\circ} \mathrm{C} / \mathrm{min}$; cooling to $-100{ }^{\circ} \mathrm{C}$ at a cooling rate of $-10{ }^{\circ} \mathrm{C} / \mathrm{min}$; second heating to $100{ }^{\circ} \mathrm{C}$ at $10{ }^{\circ} \mathrm{C} / \mathrm{min}$. The glass transition temperature $\left(T_{g}\right)$ was obtained during the cooling run, while the melting temperature $\left(T_{m}\right)$ and the enthalpy of fusion $\left(\Delta H_{m}\right)$ were obtained from both the first and the second heating runs.

Mechanical tests were performed in tensile mode with dog-bone specimens in a Zwick Z100 equipped with a $100 \mathrm{~N}$ load cell. The specimens ( $3 \mathrm{~mm}$ width and $18 \mathrm{~mm}$ parallel length) were prepared by solvent casting solutions of the polymers in chloroform. Due to the high ductility of most specimens, two loading speeds were used: $8,33 \times 10^{-5} \mathrm{~m} / \mathrm{s}$ (corresponding to $5 \mathrm{~mm} / \mathrm{min}$ ) up to an elongation of $2 \%$ for a more accurate determination of tensile modulus, and $8,33 \times 10^{-4} \mathrm{~m} / \mathrm{s}$ (corresponding to $50 \mathrm{~mm} / \mathrm{min}$ ) for higher elongations. The following mechanical properties were determined: tensile strength $\left(\sigma_{t}\right)$, yield stress $\left(\sigma_{y}\right)$, tensile modulus $\left(E_{t}\right)$, elongation at yield $\left(\varepsilon_{y}\right)$, and elongation at $\operatorname{break}\left(\varepsilon_{b}\right)$.

Statistical data analysis was performed with the "R" program and the "R-commander" package. [10,11] One-way analysis of variance (ANOVA) was used to test for differences in means of groups of samples, with Tukey Contrasts being subsequently used for the multiple comparisons of means.

\section{Results and Discussion}

We have previously optimized the biosynthesis of P4HB. [3] However, the material properties of the polymer have not been investigated. In this paper, we measured thermal and mechanical properties of both the synthesized polymer and the degraded ones.

\subsection{Evolution of the molecular weight}

Table 1 displays the evolution of molecular weight of P4HB degraded for the specified period of time. Samples degraded for more than $16 \mathrm{~h}$ could not be collected at amounts sufficient to allow further testing. The main reason was the increased difficulty in precipitating such short oligomers in methanol, resulting in a too low yield of low molecular weight fragments. This is evidenced by the morphology changes and mass reduction of the obtained polymers with degradation (Figure 1).

As shown in Figure 2, the methodology is also sensitive to the operating conditions: changes in some of those lead to clear changes in the curve profile. However, the general tendency of decay of molecular weight with degradation 
time was kept: the degradation followed a random chain scission mechanism, where degradation time is proportional to the reciprocal of the molecular weight $\left(t \propto 1 / M_{n}\right)$. [12] This mechanism is well described in literature for synthetic or bio-based polymers. $[12,13]$ We have investigated in detail the effects of process parameters (temperature, acid and/or methanol concentration) on the molecular weight evolution of medium-chain-length PHAs for such polymers, whose degradation products are more hydrophobic than ours, the linearity of a $t \times 1 / M_{n}$ curve is kept for the whole degradation time. (P. Ketikidis, "Modeling molecular weight evolution of methanolyzed medium-chainlength Poly(3-hydroxyalkanoates)", personal communication) In the current study, and mainly due to an increased methanol-solubility of short oligomers of P4HB when compared to mcl-PHA, the curve deviates from the linearity for longer degradation times; accordingly, the curve profile was also found to be more sensitive to the process parameters for longer times. Nevertheless, the optimization of the degradation procedure was not the object of this study; the goal, instead, was to determine changes in thermal and mechanical properties of our P4HB as a function of molecular weight.

\subsection{Change of thermal properties and crystallinity}

Table 2 shows the thermal properties of polymers obtained during batch 2. P4HB is a rubbery polymer, with a $T_{g}$ well below room temperature and low crystallinity. That means it may crystallize even when stored at sub-zero temperatures. To account for this effect, we extracted melting data $\left(T_{m}\right.$ and $\left.\Delta H_{m}\right)$ from both the first and second heating runs, while $T_{g}$ was measured during cooling.

In the polymer range, $T_{m}$ is usually independent of molecular weight, because the contribution of the molecular weight-independent entropic and enthalpic terms are largely exceeded by those of each repeating unit. [14] For example, in the case of PHBs, Yu and Marchessault have shown that $T_{m}$ is independent of the molecular weight of P3HB for $M_{n}>30000 \mathrm{~g} / \mathrm{mol}$. [15] In our case, the melting point was rather independent of the $M_{n}$ for the whole range; there was only a tendency to lower $T_{m}$ for the original polymer (highest molecular weight) during the second heating. Regarding the enthalpy of fusion (and, consequently, the degree of crystallinity), two important trends are clearly visible: a monotonic increase in the enthalpy of fusion for both heating runs, and a much higher value of the enthalpy in the first heating run as compared to the second one. This is also accompanied by higher values of $T_{m}$ for the first run. The differences in $T_{m}$ and $\Delta H_{m}$ between the first and second cycles may be explained by the preparation method: as described in section "Materials and Methods", specimens were prepared by precipitation in methanol, vacuum-drying at $40{ }^{\circ} \mathrm{C}$, and storage at $-20{ }^{\circ} \mathrm{C}$. Therefore, enough time and thermal energy has been supplied to allow a much higher extent of crystallization and, simultaneously, the formation of crystals with less defects and/or thicker lamellae (what increases the $T_{m}$ ). On the other hand, crystals melting during the second heating had less than 25 min (approximately the total time expended between $T_{g}$ and $T_{m}$ during cooling and second heating) to be formed. Therefore, only a smaller amount of material could crystallize, resulting in lower $\Delta H_{m}$. Moreover, during the melt crystallization, the chains do not have as high a mobility as when in the dissolved state, which contributes both to a lower degree of crystallinity (that is, lower enthalpy of fusion) and to the formation of crystals with thinner lamellae or more defects (lower $T_{m}$ ). This effect

is especially relevant for polymers of high molecular weight, because the melt viscosity and chain entanglements are too high and chain mobility is too low. This results in imperfect packing of the chains and less perfect crystals and 
could explain the slightly lower $T_{m}$ for the original P4HB, with $M_{n} \sim 10^{6} \mathrm{~g} / \mathrm{mol}$. It also leads to the decrease of the enthalpy of fusion with increase in molecular weight for both heating runs: the easiness of the large-scale molecular motions needed for chain folding and lamellae formation decreases with increasing molecular weight.

\subsection{Change of mechanical properties}

We also determined the evolution of mechanical properties of degraded P4HB. Figure 3 shows a representative curve of each sample. Original P4HB (sample "t0") shows a typical behaviour for a semi-crystalline polymer, with a well defined yield point, followed by necking/cold-drawing and a last region of strain hardening. [16] With decreasing molecular weight both the yield point and the necking region become less evident. The most degraded sample ("t4") was very brittle due to inhomogenity in the specimens. In fact, it was not possible to prepare a defect-free film of this sample.

Table 3 displays a summary of the main mechanical parameters obtained from the curves. Different mechanical properties are influenced differently by the structure of the polymer. For example, tensile strength depends on the number of ends of polymer chains and should therefore follow a relation of the type

$$
\sigma_{t}=a-b / M_{n}
$$

even if $M_{n}$ is in the polymer range. [14] The modulus, on the other hand, is mainly influenced by the degree of crystallinity; and elongation at break depends on both the degree of crystallinity and molecular weight. [14, 17] Our data in Table 3 indicates for P4HB a higher sensitivity of mechanical properties on the molecular weight than on the degree of crystallinity. Tensile strength, for example, agrees fairly well with a relation of the type shown in equation (2) (Figure 4). In fact, even the yield strength which, according to the discussion above should be more dependent on the degree of crystallinity, follows the same trend (Figure 4), being strongly influenced by the molecular weight. Moreover, the modulus was roughly constant for all degraded samples (no significant differences were observed among these samples). The main reason for this is the small change in degree of crystallinity of degraded fractions when compared to the original P4HB, as inferred from the enthalpy of fusion in Table 2. The increase in crystallinity achieved by the decrease of $M_{n}$ from $10^{6}$ to $3 \times 10^{4} \mathrm{~g} / \mathrm{mol}$ was of only about $11 \%$. This relatively small increase in crystallinity was therefore masked by the 17 -fold decrease in molecular weight of samples shown in Table 3 .

\subsection{Influence on solution and melt processing}

As mentioned previously, the melt and solvent processability of bacterial synthesized P4HB is compromised by its ultra-high molecular weight. With a $M_{n}$ close to or even above $10^{6} \mathrm{~g} / \mathrm{mol}$, P4HB is only soluble at low concentration in chlorinated solvents, and the molten polymer does not flow, even at temperatures well above the $T_{m}$ (Figure 5a). The degraded fractions, on the other hand, show a typical polymeric behaviour: a viscous fluid when molten (Figure 5aand Video in "Supporting Information") and solubility in common solvents such as acetone (Figure 5b). Fractions with $M_{n}$ between ca. $50 \cdot 10^{6} \mathrm{~g} / \mathrm{mol}$ and $300 \cdot 10^{6} \mathrm{~g} / \mathrm{mol}$ had both suitable mechanical properties (Table 3) and melt/solvent processability to allow their processing by standard polymer processing techniques. 


\section{Conclusion}

We showed here that the degradation of P4HB through random chain scission has clear effects on both thermal and mechanical properties. The decrease of molecular weight induced an increase in the degree of crystallinity, but neither the melt nor the glass transition temperature were affected. Despite this increase in crystallinity, the decrease of the molecular weight was the predominant factor controlling the mechanical properties of the degraded fractions: both the tensile strength and the modulus decreased with the decrease of molecular weight. By carefully controlling the molecular weight of the degraded polymer, materials with adequate mechanical, thermal and processability properties may be obtained to allow their use in biomedical applications as a strong yet ductile polymer.

\section{Acknowledgements}

The authors acknowledge Bernhard Henes and Eric Falk for performing the degradation experiments, Karl Kehl for the GPC, E. Falk for the DSC experiments, and Prof. Guoqiang Chen (Tsing Hua University) for providing the plasmid pKSSE5.3. KTI ("Komission für Technologie und Innovation”) is acknowledged for the partial financial support of this work through project number 12409.2 PFLS-LS.

\section{References}

[1] Y. Hori, A. Yamaguchi, T. Hagiwara, Chemical synthesis of high-molecular-weight poly(3-hydroxybutyrate-co4-hydroxybutyrate), Polymer 36 (1995) 4703-4705.

[2] S. Hein, B. Söhling, G. Gottschalk, A. Steinbüchel, Biosynthesis of poly(4-hydroxybutyric acid) by recombinant strains of Escherichia coli, FEMS Microbiol. Lett. 153 (2) (1997) 411-418.

[3] S. Le Meur, M. Zinn, T. Egli, L. Thöny-Meyer, Q. Ren, Poly(4-hydroxybutyrate) (P4HB) production in recombinant Escherichia coli: P4HB synthesis is uncoupled with cell growth, Microb. Cell. Fact. 12 (2013) 123.

[4] X.-Y. Zhou, X.-X. Yuan, Z.-Y. Shi, D.-C. Meng, W.-J. Jiang, L.-P. Wu, J.-C. Chen, G.-Q. Chen, Hyperproduction of poly(4-hydroxybutyrate) from glucose by recombinant Escherichia coli, Microb. Cell. Fact. 11 (2012) 54.

[5] D. P. Martin, S. F. Williams, Medical applications of poly-4-hydroxybutyrate: A strong flexible absorbable biomaterial, Biochem. Eng. J. 16 (2003) 97-105.

[6] T. Nelson, E. Kaufman, J. Kline, L. Sokoloff, The extraneural distribution of $\gamma$-hydroxybutyrate, J. Neurochem. 37 (1981) 1345-1348.

[7] E. K. Odermatt, L. Funk, R. Bargon, D. P. Martin, S. Rizk, S. F. Williams, MonoMax Suture: A New Long-Term Absorbable Monofilament Suture Made from Poly-4-Hydroxybutyrate, Int. J. Polym. Sci. 2012 (2012) 216137.

[8] D. P. Martin, A. Badhwar, D. V. Shah, S. Rizk, S. N. Eldridge, D. H. Gagne, A. Ganatra, R. E. Darois, S. F. Williams, H.-C. Tai, J. R. Scott, Characterization of poly-4-hydroxybutyrate mesh for hernia repair applications, J. Surg. Res. 184 (2013) 766-773. 
[9] K. Mendelson, E. Aikawa, B. A. Mettler, V. Sales, D. Martin, J. E. Mayer, F. J. Schoen, Healing and remodeling of bioengineered pulmonary artery patches implanted in sheep, Cardiovasc. Pathol. 16 (2007) $277-282$.

[10] R Core Team, R: A Language and Environment for Statistical Computing, R Foundation for Statistical Computing, Vienna, Austria, ISBN 3-900051-07-0 (2012).

URL http: //www.R-project.org/

[11] J. Fox, The R Commander: A basic statistics graphical user interface to R, J. Stat. Softw. 14 (2005) 1-42.

[12] A. A. Martens, N. A. M. Besseling, S. Rueb, E. J. R. Sudhölter, H. P. Spaink, L. C. P. M. de Smet, Random Scission of Polymers: Numerical Simulations, and Experiments on Hyaluronan Hydrolosis, Macromolecules 44 (2011) 2559-2567.

[13] M. I. A. Majid, J. Ismail, L. L. Few, C. F. Tan, The degradation kinetics of poly(3-hydroxybutyrate) under nonaqueous and aqueous conditions, Eur. Polym. J. 38 (2002) 837-839.

[14] F. W. Billmeyer Jr., Textbook of polymer science, John Wiley \& Sons, 1984, Ch. 10-12, pp. 261-360.

[15] G. Yu, R. H. Marchessault, Characterization of low molecular weight poly( $\beta$-hydroxybutyrate)s from alkaline and acid hydrolysis, Polymer 41 (2000) 1087-1098.

[16] I. M. Ward, Mechanical properties of solid polymers, John Wiley \& Sons, 1985, Ch. 11, pp. 329-373.

[17] W. D. Callister Jr., Materials science and engineering: an introduction, John Wiley \& Sons, 1997, Ch. 16, pp. $466-485$. 


\section{List of Tables}

Evolution of the molecular weight (in $\left.10^{3} \mathbf{g} / \mathbf{m o l}\right)$ during degradation $\ldots \ldots \ldots \ldots \ldots \ldots$

2 Thermal properties of original and degraded P4HB $\ldots \ldots \ldots \ldots \ldots$

3 Mechanical properties* of original and degraded P4HB $\ldots \ldots \ldots \ldots \ldots$ 
Table 1: Evolution of the molecular weight (in $10^{3} \mathbf{g} / \mathbf{m o l}$ ) during degradation

\begin{tabular}{c|c|c|c|c|c|c|c|c}
\hline \multicolumn{10}{c}{ Batch 1 } \\
\hline Time (h) & 0 & 0,25 & 0,5 & 1 & 2 & 4 & 8 & 16 \\
\hline$M_{w}$ & 2500 & 920 & 170 & 93 & 55 & 30 & 17 & 9,5 \\
$M_{n}$ & 870 & 290 & 89 & 49 & 30 & 17 & 10 & 6 \\
\hline \multicolumn{8}{|c}{ Batch 2} \\
\hline Time (h) & 0 & 0,25 & 0,85 & 1,5 & 3 & 6 & & \\
\hline$M_{w}$ & 2000 & 350 & 60 & 30 & 10 & 5 & & \\
$M_{n}$ & 1000 & 260 & 30 & 15 & 5 & 1,5 & & \\
\hline \multicolumn{10}{|c}{ Batch 3 } \\
\hline Time (h) & 0 & 0,25 & 1 & 3 & 16 & 22 & & \\
\hline$M_{w}$ & 2100 & 250 & 60 & 38 & 27 & 17 & & \\
$M_{n}$ & 520 & 170 & 29 & 19 & 51 & 9,2 & & \\
\hline
\end{tabular}


Table 2: Thermal properties of original and degraded P4HB

\begin{tabular}{c|c|c|c|c|c}
\hline & \multicolumn{2}{|c|}{ First heating run } & \multicolumn{2}{c|}{ Second heating run } & Cooling \\
\hline$M_{n}\left(10^{3} \mathrm{~g} / \mathrm{mol}\right)$ & $T_{m}\left({ }^{\circ} \mathrm{C}\right)$ & $-\Delta H_{m}(\mathrm{~J} / \mathrm{g})$ & $T_{m}\left({ }^{\circ} \mathrm{C}\right)$ & $-\Delta H_{m}(\mathrm{~J} / \mathrm{g})$ & $T_{g}\left({ }^{\circ} \mathrm{C}\right)$ \\
\hline 1000 & 69 & 63,8 & 57 & 36,5 & -52 \\
260 & 69 & 64,7 & 61 & 37,6 & -52 \\
30 & 69 & 70,5 & 63 & 42,5 & -51 \\
15 & 66 & 78,5 & 63 & 51,1 & -49 \\
5 & 69 & 85,5 & 61 & 56,4 & -50 \\
\hline
\end{tabular}


Table 3: Mechanical properties* of original and degraded P4HB

\begin{tabular}{c|c|c|c|c|c|c}
\hline Sample & $M_{n}\left(10^{3} \mathrm{~g} / \mathrm{mol}\right)$ & $\sigma_{t}(\mathrm{MPa})$ & $E_{t}(\mathrm{GPa})$ & $\varepsilon_{b}(\%)$ & $\sigma_{y}(\mathrm{MPa})$ & $\varepsilon_{y}(\%)$ \\
\hline $\mathrm{t} 0$ & 520 & $28^{a}$ & $0,17^{a}$ & $520^{a}$ & $13^{a}$ & $17^{a}$ \\
$\mathrm{t} 1$ & 290 & $17^{b}$ & $0,12^{b}$ & $450^{a b}$ & $9,6^{b}$ & $12^{b}$ \\
t2 & 90 & $16^{b}$ & $0,12^{b}$ & $470^{a b}$ & $8,4^{b}$ & $10^{b c}$ \\
t3 & 50 & $11^{b c}$ & $0,13^{b}$ & $220^{b}$ & $7,8^{b c}$ & $10^{b c}$ \\
t4 & 30 & $5,3^{c}$ & $0,10^{b}$ & 10 & $5,3^{c}$ & $6,1^{c}$ \\
\hline
\end{tabular}

The superscripts identify samples in the same column with significantly different values (at $p<0,05)$ for the corresponding property.

* Tensile strength $\left(\sigma_{t}\right)$, tensile modulus $\left(E_{t}\right)$, elongation at break $\left(\varepsilon_{b}\right)$, yield stress $\left(\sigma_{y}\right)$, and elongation at yield $\left(\varepsilon_{y}\right)$. 


\section{List of Figures}

1 Morphology change of the obtained P4HB after degradation. A, B, C, D, E, F, G, and H represent the P4HB after degradation of $0,0.25,0.5,1,2,4,8$, and $16 \mathrm{~h}$, respectively. . . . . . . . . .

2 Evolution of the molecular weight with degradation time. Differences in the curve profile arise from differences in operator, volume of the aliquot removed at each time point, or in the method used to recover the polymer, showing the sensitivity of the degradation protocol to the process parameters. Lines are only to guide the eyes. . . . . . . . . . . . . . . . . . . . 15

3 Tensile curves of a representative specimen of each sample of original and degraded P4HB. . . . 16

4 Tensile $\left(\sigma_{t}\right)$ and yield $\left(\sigma_{y}\right)$ strength as a function of the molecular weight. The fitting of each dataset with equation (2) is also shown: $\sigma_{t}=23,574-581103 * \mathrm{x}\left(r^{2}=0,81\right)$, and $\sigma_{y}=11,703-217927 * \mathrm{x}$ $\left(r^{2}=0,85\right)$.

(a) Molten original and degraded $\mathrm{P} 4 \mathrm{HB}$ at $100{ }^{\circ} \mathrm{C}$. (b) Solubility of original and degraded $\mathrm{P} 4 \mathrm{HB}$ in acetone after $24 \mathrm{~h}$ at room temperature. There is a clear precipitate in the solution of the two original P4HB specimens; all others are clear solutions. For both images, the molecular weight $\left(M_{n}\right.$, in $10^{3} \mathrm{~g} / \mathrm{mol}$ ) is (from left to right): 520 (foam), 520 (film), 290, 90, 50, 30, and $17 . \ldots \ldots \ldots$ 


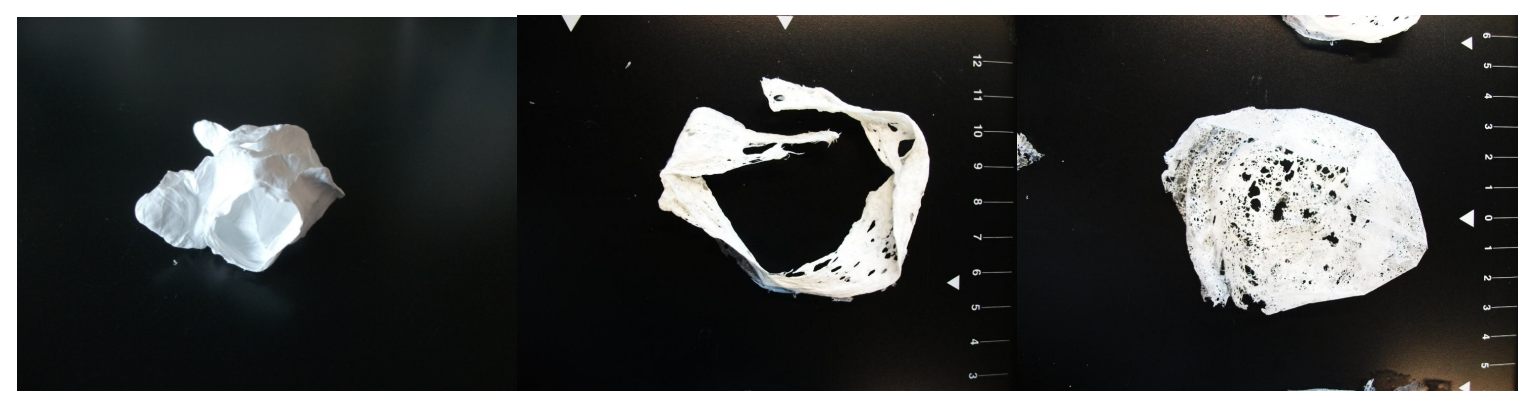

(a)

(b)

(c)

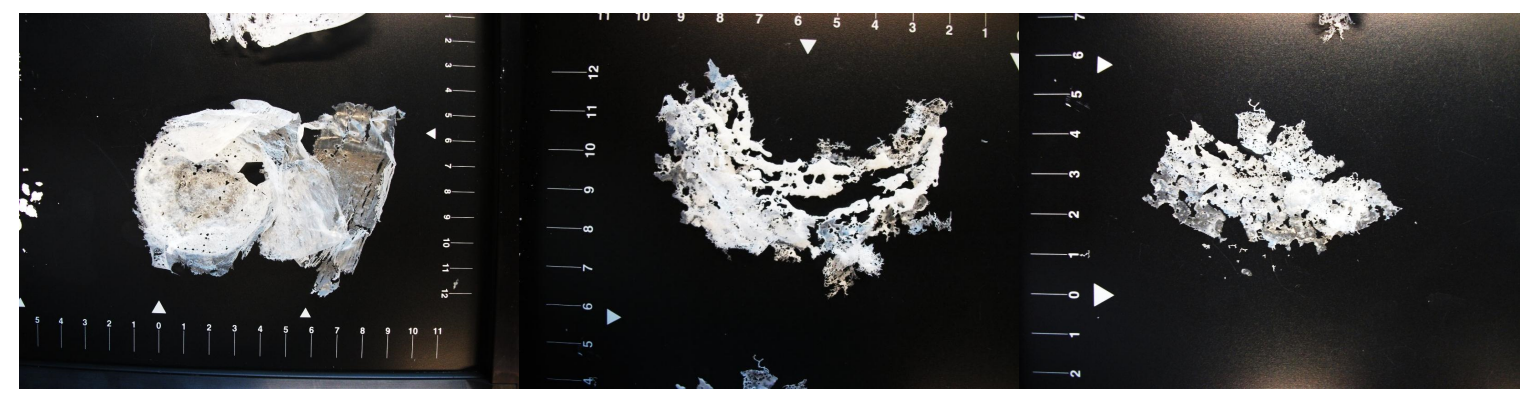

(d)

(e)

(f)

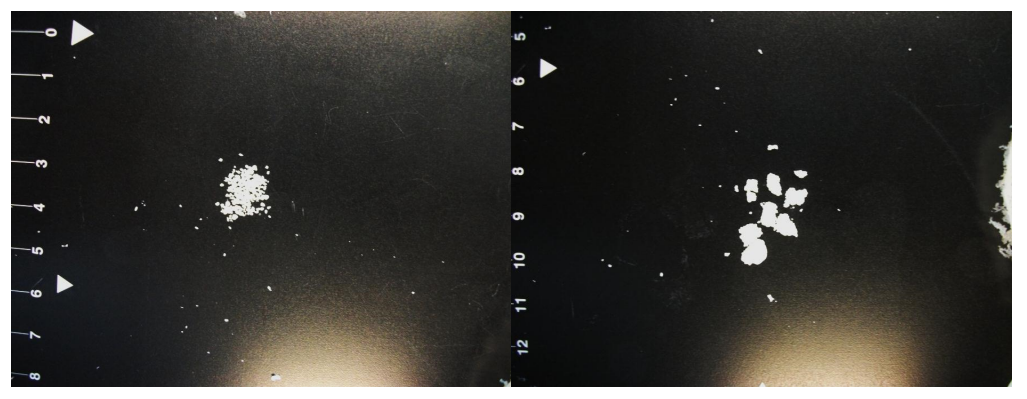

(g)

(h)

Figure 1: Morphology change of the obtained P4HB after degradation. A, B, C, D, E, F, G, and $\mathrm{H}$ represent the $\mathrm{P} 4 \mathrm{HB}$ after degradation of $0,0.25,0.5,1,2,4,8$, and $16 \mathrm{~h}$, respectively. 


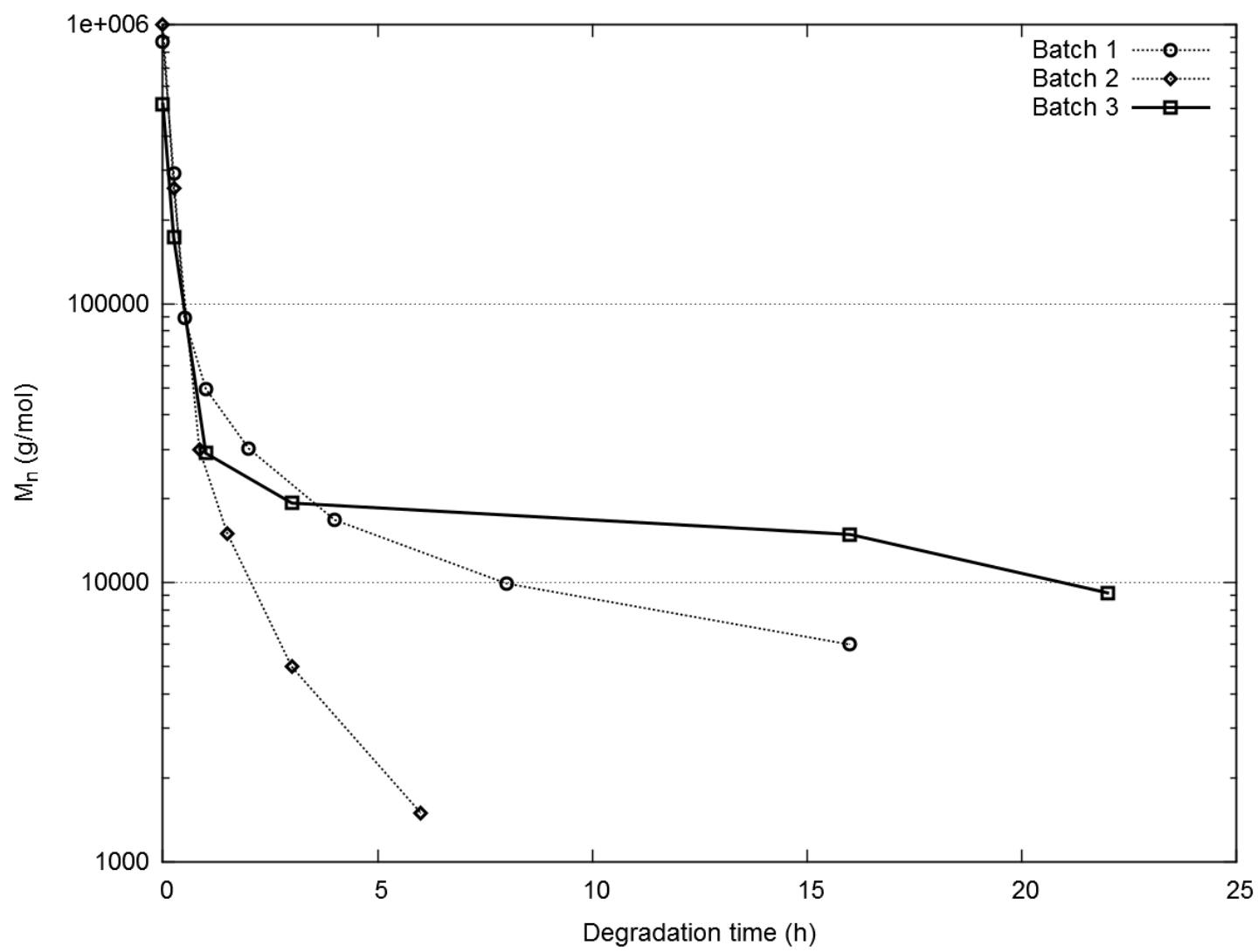

Figure 2: Evolution of the molecular weight with degradation time. Differences in the curve profile arise from differences in operator, volume of the aliquot removed at each time point, or in the method used to recover the polymer, showing the sensitivity of the degradation protocol to the process parameters. Lines are only to guide the eyes. 


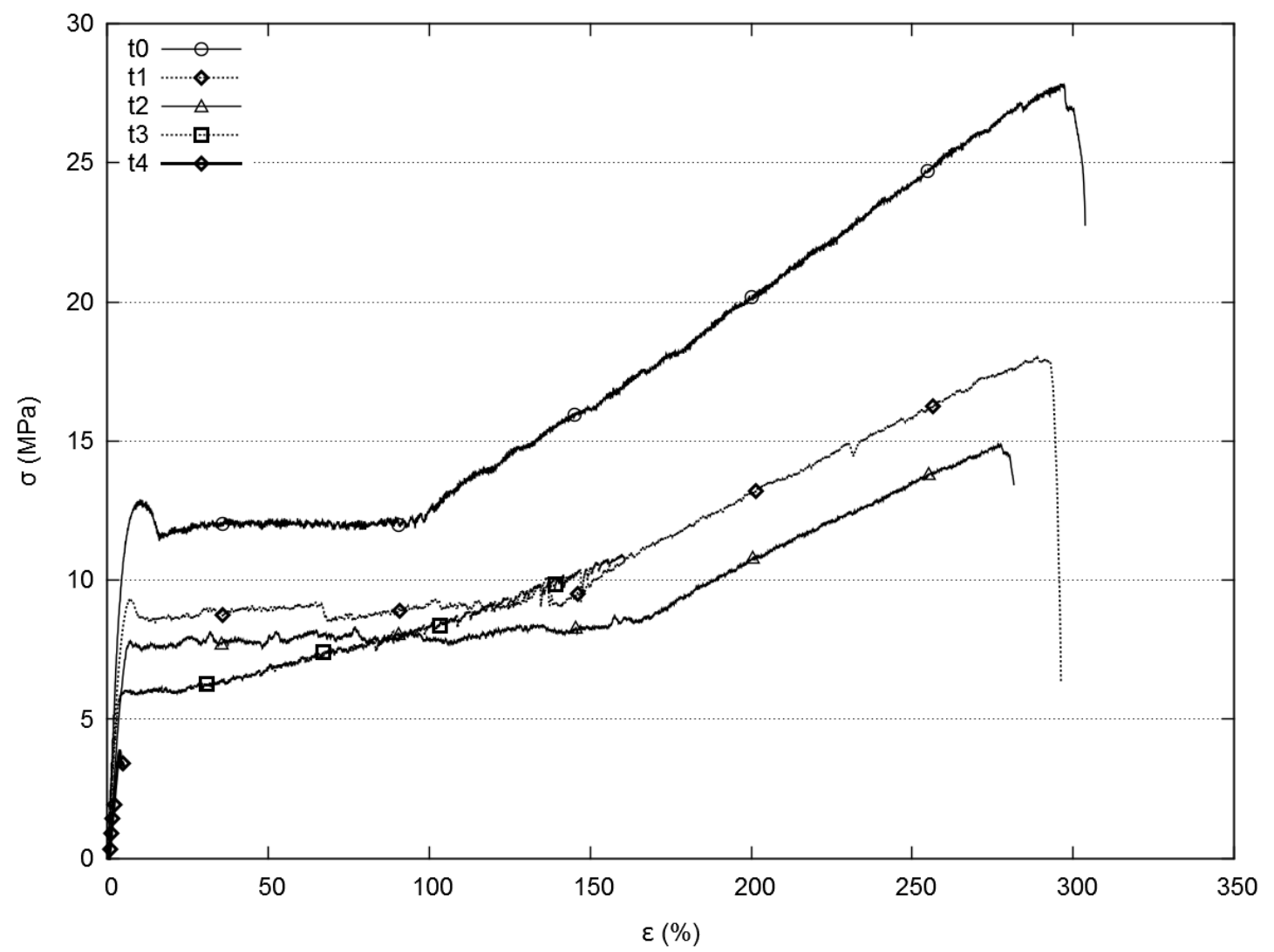

Figure 3: Tensile curves of a representative specimen of each sample of original and degraded P4HB. 


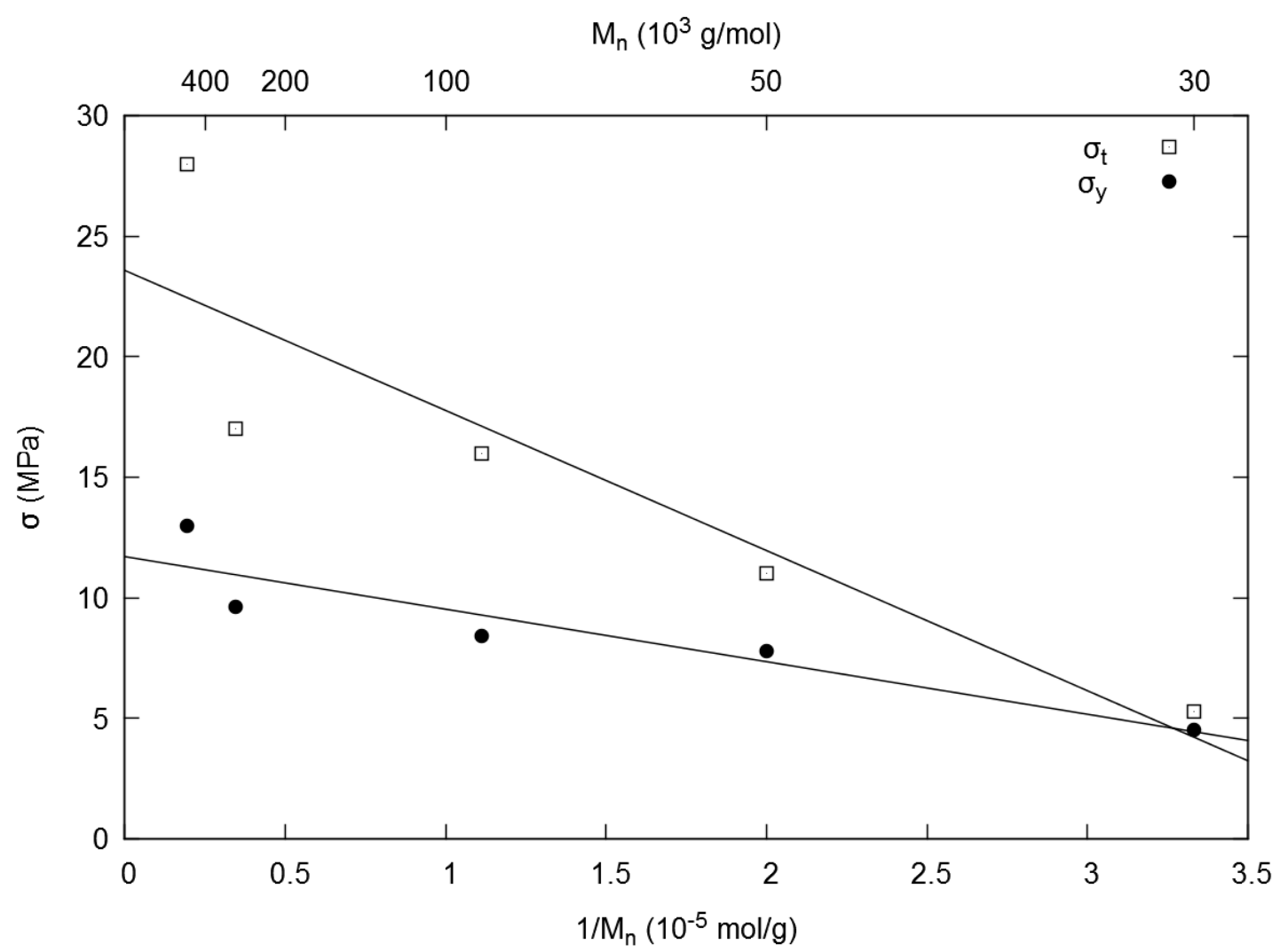

Figure 4: Tensile $\left(\sigma_{t}\right)$ and yield $\left(\sigma_{y}\right)$ strength as a function of the molecular weight. The fitting of each dataset with equation (2) is also shown: $\sigma_{t}=23,574-581103 * \mathrm{x}\left(r^{2}=0,81\right)$, and $\sigma_{y}=11,703-217927 * \mathrm{x}\left(r^{2}=0,85\right)$. 


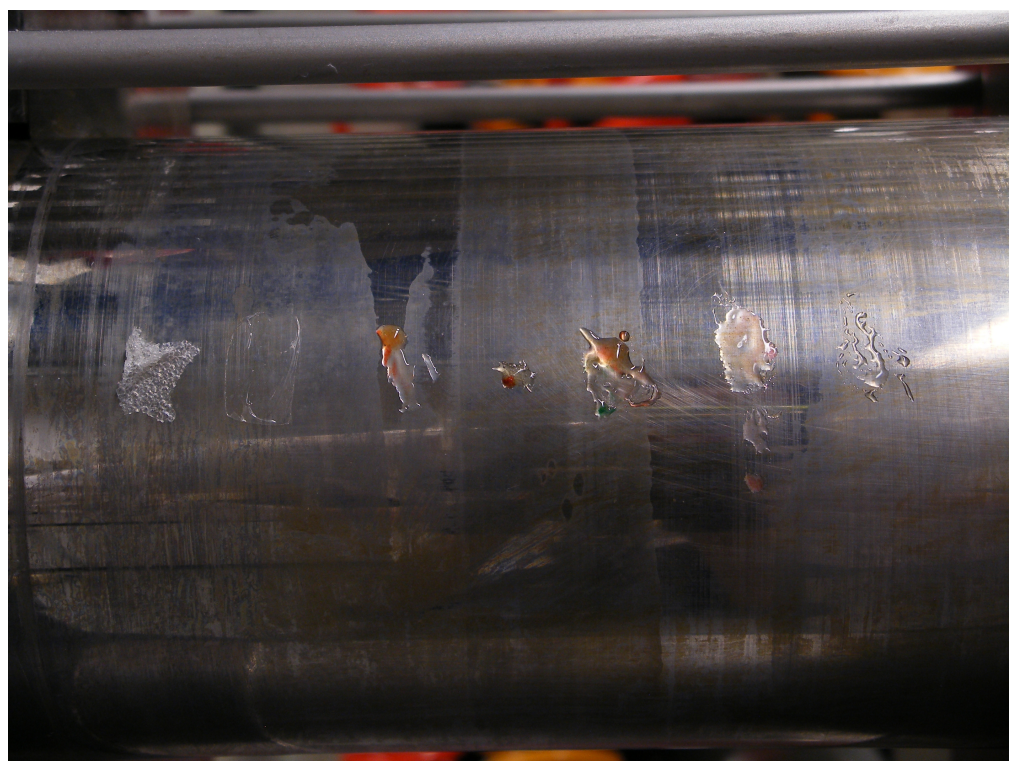

(a)

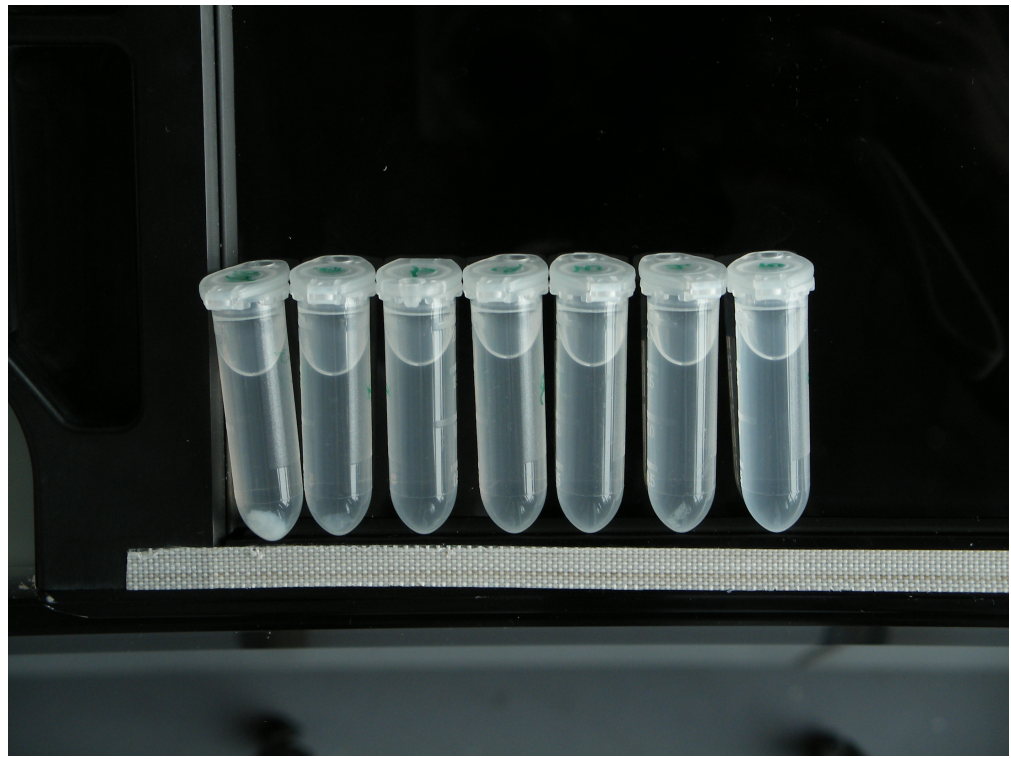

(b)

Figure 5: (a) Molten original and degraded P4HB at $100{ }^{\circ} \mathrm{C}$. (b) Solubility of original and degraded P4HB in acetone after $24 \mathrm{~h}$ at room temperature. There is a clear precipitate in the solution of the two original $\mathrm{P} 4 \mathrm{HB}$ specimens; all others are clear solutions. For both images, the molecular weight $\left(M_{n}\right.$, in $\left.10^{3} \mathrm{~g} / \mathrm{mol}\right)$ is (from left to right): 520 (foam), 520 (film), 290, 90, 50, 30, and 17. 